\title{
ALGORITMA IMAGE THINNING
}

\author{
Oleh
}

\author{
Zurnawita dan Zulharbi Suar
}

Staf Pengajar Teknik Elektro Politeknik Negeri Padang

\begin{abstract}
Using image thinning algorithm, various example of application is processing image to become more and more variate and helpfully for recognition process an image such as were studied by example. First, this handout will be explained some term which concerning image thinning in digital image processing, then definition from image thinning and algorithm to process image thinning at one particular digital image will be explained. In the next will be given an image thinning application which used for Extraction of Filarial Worms.
\end{abstract}

Keywords: Image thinning, Algor

\section{PENDAHULUAN}

Pada saat sekarang ini teknologi komputer telah berkembang pesat. Teknologi komputer ini pada mulanya hanya berkembang dalam teknologi pengolahan data saja. Namun seiring perkembangan zaman dan teknologi di bidang lain, maka teknologi komputer saat ini pun ikut menyesuaikan diri. Salah satu yang sedang pesat berkembang adalah teknologi komputer dalam bidang multimedia, dimana bidang multimedia saat ini sedang menjadi pusat perhatian. Teknologi komputer multimedia ini meliputi pengolahan gambar (image), audio, video, dan lain sebagainya.

Sejak kemunculan pertama gambar digital tahun 1920, terutama munculnya aplikasi dalam teknologi komputer dalam memproses gambar digital tahun 1960 pemoresaan sebuah gambar dalam komputer menjadi lebih mudah. Teknologi pencitraan komputer yang berkembang dengan cepat dan mencapai hasil yang hebat dalam menggantikan, bahkan melampaui kehebatan penglihatan manusia.

Teknologi pemrosesan citra oleh komputer banyak digunakan pada berbagai aplikasi, baik kedokteran, biologi, geografis, dan banyak lainnya. Dalam teknik pengolahan gambar/citra (image) ini dikenal suatu teknik pengenalan pola atau pattern recognition. Salah satu proses awal dalam pattern recognition adalah penipisan gambar, yang lebih dikenal dengan image thinning. Dalam sebuah aplikasi biasanya image thinning dikombinasikan dengan berbagai fungsi lain, seperti skeletoning, region filling, hit or miss, dan sebagainya.

Melihat manfaat thinning sebagai preprocessing operation untuk proses pengolahan gambar atau citra selanjutnya, maka pada makalah kali ini akan dijelaskan mengenai thinning, termasuk beberapa algoritma yang dapat digunakan untuk melakukan proses thinning tersebut. 


\section{STRUKTURE IMAGE THINNING}

\section{Definisi Beberapa Terminologi}

Thinning merupakan salah satu algoritma perubahan citra dalam morphological operation. Berdasarkan etimologi bahasa, morphology berasal dari kosakata bahasa Jerman yaitu morphologie yang terdiri dari morph+logie/logy. Morph adalah suatu kata kerja yang berupa singkatan dari metamorphose yang artinya perubahan bentuk atau karakter akibat perubahan pada struktur atau komposisi (transformasi). Sesuai dengan arti dasarnya, konsep Morphological Operation pada pengolahan citra adalah operasi-operasi perubahan bentuk pada binary image atau grayscale image. Berbagai jenis Morphological Operation antara lain : Erosion, dilation, opening, closing, thinning dan thickness.

Binary image adalah citra yang direpresentasikan sebagai himpunan dari pixel-pixel foreground (obyek depan). Binary image merupakan citra yang hanya mempunyai dua informasi intensitas warna, yaitu hitam dan putih. Konvensi untuk menentukan intensitas warna pada binary image bisa berbedabeda, namun pada umumnya digunakan konvensi yang mendeskripsikan nilai 0 sebagai warna hitam dan nilai 1 atau 255 sebagai warna putih. Warna putih biasanya juga digunakan untuk warna foreground, sedangkan warna hitam adalah warna background, namun sekali lagi ketentuan ini bukan merupakan keharusan tergantung dari binary image yang dihasilkan. Binary image seringkali dihasilkan dari proses thresholding suatu grayscale image (citra yang memiliki informasi tingkat keabuan) dan color image (citra yang memiliki informasi intensitas warna yang bervariasi).

Pada setiap operasi morphology selalu diperlukan adanya structuring element/SE atau yang biasa disebut dengan kernel, yaitu basis atau matriks yang menentukan detil-detil tertentu akibat pengaruh suatu operator pada citra. SE/Kernel mempunyai bermacammacam ukuran/dimensi/orde matriks, masing-masing mempunyai satu origin yang bisa terletak dimana saja, namun pada umumnya origin terletak di entry tengah pada matriks. SE juga memiliki satu atau lebih entry kosong (empty spots) yang dianggap don't care.

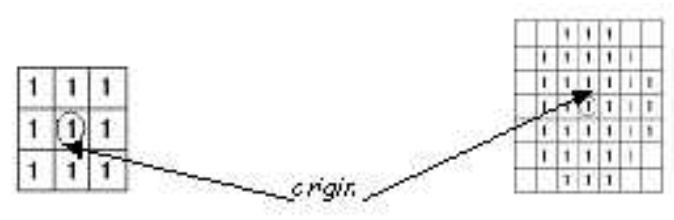

Gambar 1. structuring element/ kernel

\section{Definisi, Tujuan dan Manfaat \\ Thinning}

Definisi image thinning adalah proses morphology image yang merubah bentuk asli binary image menjadi image yang menampilkan batas-batas obyek/foreground hanya setebal satu pixel. Algoritma thinning secara iteratif 'menghapus' pixel-pixel pada binary image, dimana transisi dari 0 ke 1 (atau dari 1 ke 0 pada konvensi lain) terjadi sampai dengan terpenuhi suatu keadaan dimana satu himpunan dari lebar per unit (satu pixel) terhubung menjadi suatu garis. Morphological thinning dari binary image oleh SE juga melibatkan proses hit-or-miss transform.

Sepintas, image thinning mempunyai kemiripan dengan edge detection dalam hal output dari citra yang dihasilkan, kedua proses tersebut sama-sama menampilkan batas obyek pada citra. Namun, tetap saja ada perbedaaan antara Image Thinning dengan Edge Detection dari segi prinsip kerjanya, yaitu:

- Edge detection : merubah graylevel image atau color image menjadi image yang menampilkan batas- 
batas/boundaries obyek berdasarkan kekontrasan warna antar pixel.

- Image Thinning : mereduksi pixelpixel pada obyek binary image menjadi pixel yang benilai sama dengan nilai pixel pada background. Menghasilkan binary image dengan informasi berupa batas-batas obyek berdasarkan pixel dengan ketebalan satu pixel.

Tujuan image thinning adalah untuk menghilangkan pixel-pixel yang berada didalam obyek depan (foreground object) pada binary images.

Manfaat image thinning adalah sebagai berikut:

- biasanya diterapkan pada proses skeletonisasi.

- Berguna untuk merapikan/menyempurnakan hasil output proses edge detection dengan cara mengurangi lebar sisi/batas/edge.

\section{Algoritma Strukture Image Thinning}

Thinning merupakan metode yang digunakan untuk skeletonizing yang salah satu penggunaanya adalah dalam aplikasi pattern recognition. Terdapat cukup banyak algoritma untuk image thinning dengan tingkat kompleksitas, efisiensi dan akurasi yang berbeda-beda. Citra yang digunakan adalah citra biner, jika citra itu merupakan suatu citra grayscale, biasanya dilakukan thresholding terlebih dahulu sedemikian rupa sehingga citra tersebut menjadi citra biner. Citra biner adalah citra yang hanya memiliki 2 kemungkinan nilai pada setiap piksel-pikselnya, yaitu 0 atau 1. Nilai 0 adalah background points, biasanya bukan merupakan bagian dari citra sesungguhnya. Sedangkan nilai 1 adalah region points, yaitu bagian dari citra sebenarnya (bukan latar belakang). Citra hasil dari algoritma thinning biasanya disebut dengan skeleton.
Umumnya suatu algoritma thinning yang dilakukan terhadap citra biner seharusnya memenuhi kriteriakriteria sebagai berikut:

a. Skeleton dari citra kira-kira berada di bagian tengah dari citra awal sebelum dilakukan thinning.

b. Citra hasil dari algoritma thinning harus tetap menjaga struktur keterhubungan yang sama dengan citra awal.

c. Suatu skeleton seharusnya memiliki bentuk yang hampir mirip dengan citra awal.

d. Suatu skeleton seharusnya mengandung jumlah pixel yang seminimal mungkin namun tetap memenuhi kriteria-kriteria sebelumnya.

\section{Algoritma Dan Proses Thinning}

Ada beberapa algoritma yang digunakan dalam proses thinning. Diantaranya adalah metode Stentiford dan metode Zhan-Suen.

Stentiford method menggunakan template-based mark-and-delete thinning algorithm. Algoritma ini menggunakan template matching, dimana jika bagian dari gambar sesuai dengan template, hapus pixel yang di tengah.

Zhan-Suen method menggunakan metode iterasi, yang berarti nilai yang baru didapat dari proses sebelumnya. Cara ini mudah untuk diimplementasikan.

\section{Thinning dengan Algoritma Zhang Suen}

Algoritma ini adalah salah satu algoritma thinning yang cukup populer dan telah digunakan sebagai suatu basis perbandingan untuk thinning. Algoritma ini cepat dan mudah diimplementasikan. Setiap iterasi dari metode ini terdiri dari dua sub-iterasi yang berurutan yang dilakukan terhadap contour points dari wilayah citra. Contour point adalah 
setiap pixel dengan nilai 1 dan memiliki setidaknya satu 8-neighbor yang memiliki nilai 0 .

Dengan informasi ini, langkah pertama adalah menandai contour point $\mathrm{p}$ untuk dihapus jika semua kondisi ini dipenuhi:
(a) $2 \leq \mathrm{N}\left(\mathrm{p}_{1}\right) \leq 6$;
(b) $\mathrm{S}\left(\mathrm{p}_{1}\right)=1$;
(c) $\mathrm{p}_{2} \cdot \mathrm{p}_{4} \cdot \mathrm{p}_{6}=0$;
(d) $\mathrm{p}_{4} \cdot \mathrm{p}_{6} \cdot \mathrm{p}_{8}=0$;

dimana $\mathrm{N}\left(\mathrm{p}_{1}\right)$ adalah jumlah tetangga dari $\mathrm{p}_{1}$ yang tidak 0 ; yaitu, $\mathrm{N}\left(\mathrm{p}_{1}\right)=\mathrm{p}_{2}+\mathrm{p}_{3}+\ldots+\mathrm{p}_{8}+\mathrm{p}_{9}$

\begin{tabular}{|l|l|l|}
\hline $\mathrm{p}_{9}$ & $\mathrm{p}_{2}$ & $\mathrm{p}_{3}$ \\
\hline $\mathrm{p}_{8}$ & $\mathrm{p}_{1}$ & $\mathrm{p}_{4}$ \\
\hline $\mathrm{p}_{7}$ & $\mathrm{p}_{6}$ & $\mathrm{p}_{5}$ \\
\hline
\end{tabular}

dan $\mathrm{S}\left(\mathrm{p}_{1}\right)$ adalah jumlah dari transisi 0-1 pada urutan $\mathrm{p}_{2}, \mathrm{p}_{3}, \ldots, \mathrm{p}_{8}, \mathrm{p}_{9}$.

Dan pada langkah kedua, kondisi (a) dan (b) sama dengan langkah pertama, sedangkan kondisi (c) dan (d) diubah menjadi:

(c') $\mathrm{p}_{2} \cdot \mathrm{p}_{4} \cdot \mathrm{p}_{8}=0$;

(d') $\mathrm{p}_{2} \cdot \mathrm{p}_{6} \cdot \mathrm{p}_{8}=0$; Langkah pertama dilakukan terhadap semua border pixel di citra. Jika salah satu dari keempat kondisi di atas tidak dipenuhi atau dilanggar maka nilai piksel yang bersangkutan tidak diubah. Sebaliknya jika semua kondisi tersebut dipenuhi maka piksel tersebut ditandai untuk penghapusan.

Piksel yang telah ditandai tidak akan dihapus sebelum semua border points selesai diproses. Hal ini berguna untuk mencegah perubahan struktur data. Setelah langkah 1 selesai dilakukan untuk semua border points maka dilakukan penghapusan untuk titik yang telah ditandai (diubah menjadi 0). Setelah itu dilakukan langkah 2 pada data hasil dari langkah 1 dengan cara yang sama dengan langkah 1 sehingga, dalam satu kali iterasi urutan algoritmanya terdiri dari:

1. Menjalankan langkah 1 untuk menandai border points yang akan dihapus,

2. Hapus titik-titik yang ditandai dengan menggantinya menjadi angka 0 ,

3. Menjalankan langkah 2 pada sisa border points yang pada langkah 1 belum dihapus lalu yang sesuai dengan semua kondisi yang seharusnya dipenuhi pada langkah 2 kemudian ditandai untuk dihapus,

4. Hapus titik- titik yang ditandai Dengan menggantinya menjadi angka 0 .

Prosedur ini dilakukan secara iteratif sampai tidak ada lagi titik yang dapat dihapus, pada saat algoritma ini selesai maka akan dihasilkan skeleton dari citra awal

Contoh proses thinning dengan Algoritma Zhang Suen

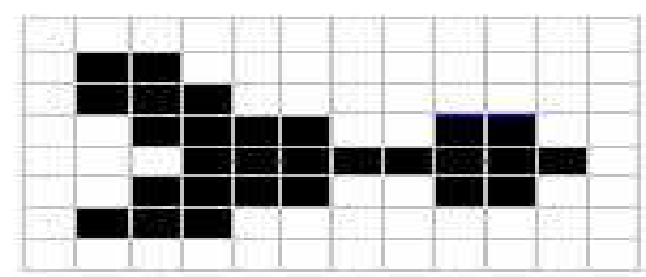

Gambar 2. Sebelum proses thinning

Langkah-langkahnya:

a. Beri tanda semua piksel 8-tetangga yang memenuhi kondisi (1) sampai dengan (4).

b. Hapus piksel tengahnya.

c. Beri tanda semua piksel 4-tetangga yang memenuhi kondisi (5) sampai dengan (8).

d. Hapus piksel tengahnya.

Lakukan langkah a sampai d berulang kali, sampai tidak ada perubahan. 
Kondisi:

(1) $2 \leq \mathrm{N}\left(\mathrm{p}_{1}\right) \leq 6$

(2) $\mathrm{S}\left(\mathrm{p}_{1}\right)=1$

(3) $\mathrm{p}_{2} \bullet \mathrm{p}_{4} \bullet \mathrm{p}_{6}=0$

(4) $\mathrm{p}_{4} \bullet \mathrm{p}_{6} \bullet \mathrm{p}_{8}=0$

(5) $2 \leq \mathrm{N}\left(\mathrm{p}_{1}\right) \leq 6$

(6) $\mathrm{S}\left(\mathrm{p}_{1}\right)=1$

(7) $\mathrm{p}_{2} \bullet \mathrm{p}_{4} \bullet \mathrm{p}_{8}=0$

(8) $\mathrm{p}_{2} \bullet \mathrm{p}_{6} \bullet \mathrm{p}_{8}=0$

Dimana:

$\mathrm{N}\left(\mathrm{p}_{1}\right)=$ jumlah dari tetangga $\mathrm{p} 1$ yang tidak nol

$\mathrm{S}\left(\mathrm{p}_{1}\right)=$ jumlah transisi $0-1$ dalam urutan $\mathrm{p}_{2}$,

$\mathrm{p}_{3}, \ldots$

Penamaan piksel :

\begin{tabular}{|l|l|l|}
\hline $\mathrm{p} 9$ & $\mathrm{p} 2$ & $\mathrm{p} 3$ \\
\hline $\mathrm{p} 8$ & $\mathrm{p} 1$ & $\mathrm{p} 4$ \\
\hline $\mathrm{p} 7$ & $\mathrm{p} 6$ & $\mathrm{p} 5$ \\
\hline
\end{tabular}

Jika pada Gambar 2. dilakukan proses thinning, maka gambar akan menjadi:

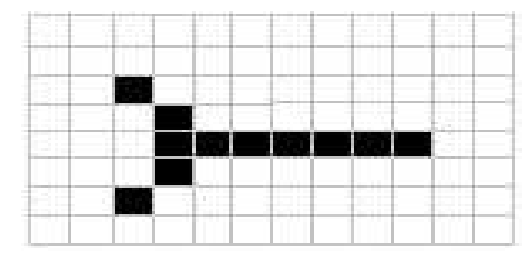

Gambar 3. Setelah proses thinning

\section{Thinning dengan Algoritma Stentiford}

Metode ini adalah algoritma thinning dengan menggunakan teknik template-based mark-and-delete. Metode ini cukup terkenal karena reliable dan kefektifannya. Metode thinning jenis ini menggunakan template untuk dicocokkan dengan citra yang akan dithinning. Algoritma ini bersifat iteratif yang berguna untuk mengikis lapisan pixel terluar sampai tidak ada lapisan lagi yang dapat dihilangkan.

Template yang dipakai adalah 4 buah template 3 x 3 yaitu,
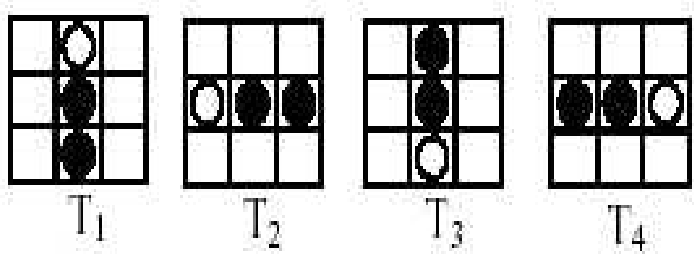

Gambar 4. Template $3 \times 3$

Berikut ini akan dijelaskan langkahlangkah algoritma Stentiford:

1. Tandai pixel tersebut untuk kemudian dihilangkan (remove).

2. Endpoint pixel : cari pixel pada lokasi (i,j) dimana pixel-pixel pada image cocok dengan template $\mathrm{T}_{1}$. Dengan template ini, maka semua pixel di bagian atas dari image akan dihilangkan (remove). Pencocokkan template ini bergerak dari kiri ke kanan dan dari atas ke bawah.

Bila pixel tengah bukan merupakan endpoint dan mempunyai jumlah konektivitas (connectivity number) 1 , merupakan batas akhir dan hanya terhubung dengan 1 pixel saja. Contoh: suatu pixel hitam hanya mempunyai satu tetangga saja yang hitam juga dari kemungkinan delapan tetangga.

\section{Connectivity number}

merupakan suatu ukuran berapa banyak obyek yang terhubung dengan pixel tertentu (dihitung berdasarkan rumus di bawah).

$C_{n}=\sum_{k=5} N_{k}-\left(N_{k} \cdot N_{k+1} \cdot N_{k+12}\right)$

$\mathrm{N}_{\mathrm{k}}$ merupakan nilai dari 8 tetangga di sekitar pixel yang akan dianalisa (central pixel) dan nilai $\mathrm{S}=\{1,3,5,7\} . \mathrm{N}_{0}$ adalah nilai dari pixel tengah (central pixel). $\mathrm{N}_{1}$ adalah nilai dari pixel pada sebelah kanan central pixel dan sisanya diberi nomor berurutan dengan arah berlawanan jarum jam. 


\begin{tabular}{|l|l|l|}
\hline 4 & 3 & 2 \\
\hline 5 & 0 & 1 \\
\hline 6 & 7 & 8 \\
\hline
\end{tabular}

Contoh :
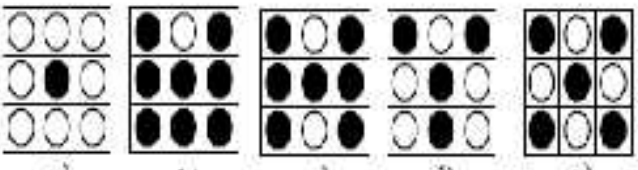

b)

e)

Bagian a) menjelaskan tentang jumlah konektivitas (connectivity number) $=0$.

Bagian b) menjelaskan tentang jumlah konektivitas (connectivity number) $=1$.

Bagian c) menjelaskan tentang jumlah konektivitas (connectivity number) $=2$.

Bagian d) menjelaskan tentang jumlah konektivitas (connectivity number) $=3$.

Bagian e) menjelaskan tentang jumlah konektivitas (connectivity number) $=3$

3. Ulangi langkah 1 dan 2 untuk semua pixel yang cocok dengan template $\mathrm{T}_{1}$.

4. Ulangi langkah 1-3 untuk template $\mathrm{T}_{2}, \mathrm{~T}_{3}$ dan $\mathrm{T}_{4}$.

Pencocokkan template $\mathrm{T}_{2}$ akan dilakukan pada sisi kiri dari obyek dengan arah dari bawah ke atas dan dari kiri ke kanan.

Pencocokkan template $\mathrm{T}_{3}$ akan dilakukan pada sisi bawah dari obyek dengan arah dari kanan ke kiri dan dari bawah ke atas.

Pencocokkan template $\mathrm{T}_{4}$ akan dilakukan pada sisi kanan dari obyek dengan arah dari atas ke bawah dan dari kanan ke kiri.

5. Pixel-pixel yang ditandai untuk dihilangkan (remove) dibuat sama dengan background (di-set 0 untuk binary image).

\section{Contoh Hasil Thinning \\ Gambar Asli \\ Gambar 1}

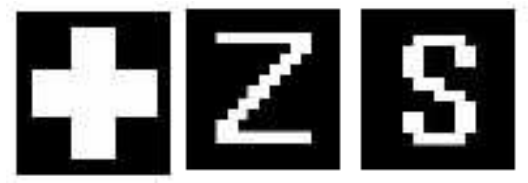

Gambar 2

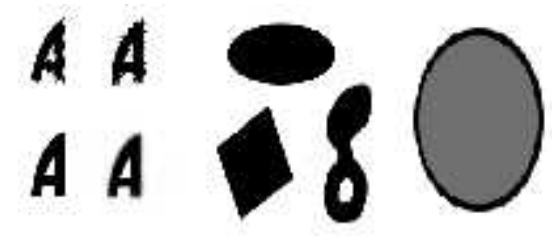

\section{Dengan algoritma Zhang-Suen}

Citra setelah di-thinning :

Gambar 1:

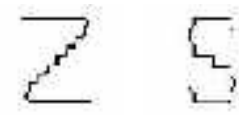

Gambar 2:
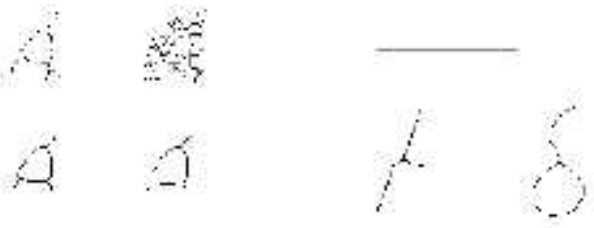

\section{Aplikasi Strukture Image Thinning}

Pada contoh berikut ini, image thinning digunakan untuk mengekstraksi citra cacing filaria dari suatu citrayang didapat.

http://www.dca.fee.unicamp.br/projects/ khoros/mmach/tutor/application/biologic al/fila/fila.html. Berikut adalah langkahlangkahnya:

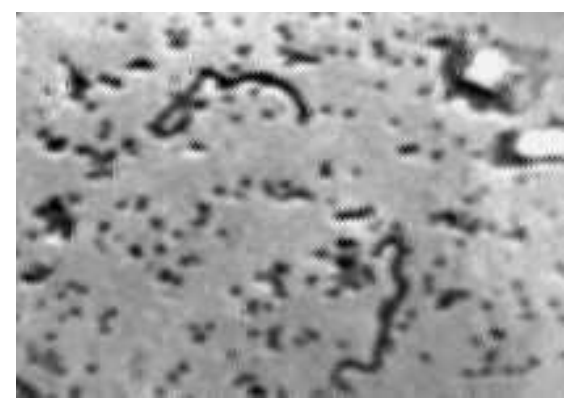

Gambar 5. Citra mikroskopik dari transmiter cacing filaria. 


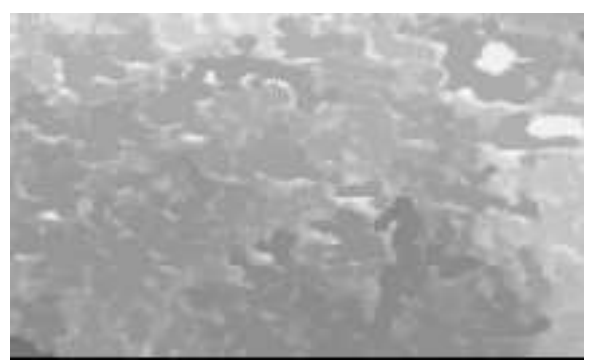

Gambar 6 Closing by reconstruction

Pada citra tersebut dilakukan filter morfologis untuk memisahkan bagianbagiannya yang terlihat berlubang. Filtering ini dilakukan dengan closing by reconstruction.

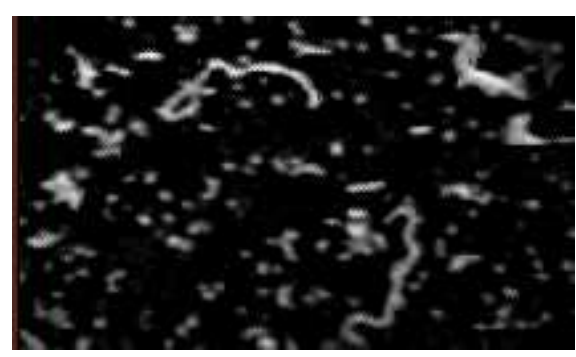

Gambar 7. Subtraction

Selanjutnyadilakukan morphological subtraction Gambar 5 dari Gambar 6 yang menghasilkan Gambar 7.

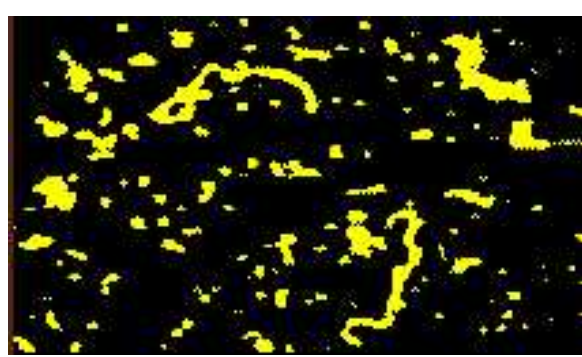

Gambar 8. Thresholding

Berikutnya dilakukan thresholding pada gambar, yang menghasilkan Gambar 8 .

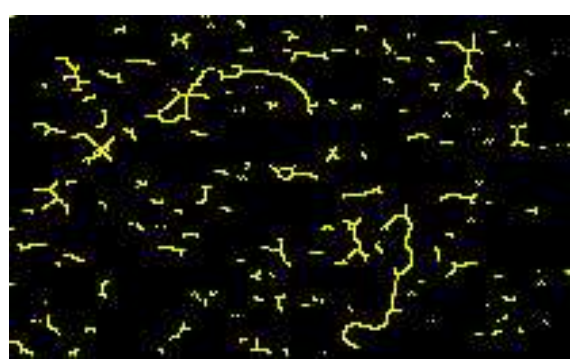

Gambar 9. Skeletonization

Sekarang tujuannya adalah untuk membedakan cacing filaria dari obyek yang lain. Hal itu dapat dilakukan dengan mengingat fakta bahwa cacing filaria lebih panjang daripada obyek lain. Sehingga tinggal mencari tanda untuk obyek terpanjang dari binary image. Aplikasikan skeleton dengan cara thinning pada Gambar 9.

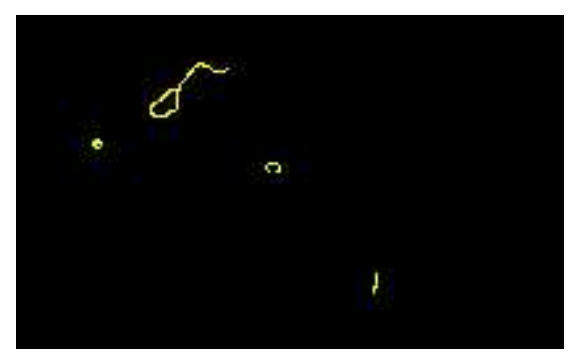

Gambar 10. N-Thinning

Dilanjutkan oleh N-Thinning pada Gambar 10.

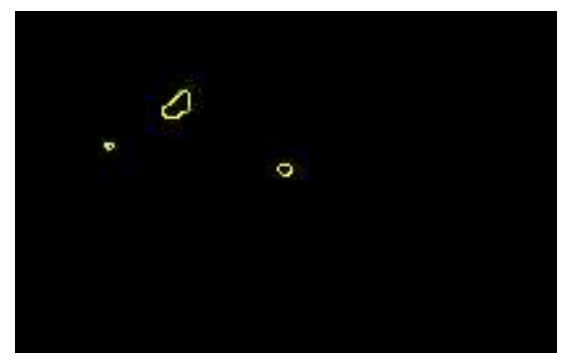

Gambar 11. Skeletonization

Tail dari citra di atas bisa menjadi tanda yangdiinginkan. Untuk mendapatkannya, kita bisa mengaplikasikan skeleton yang akan menghabiskan citra pada Gambar 10. 


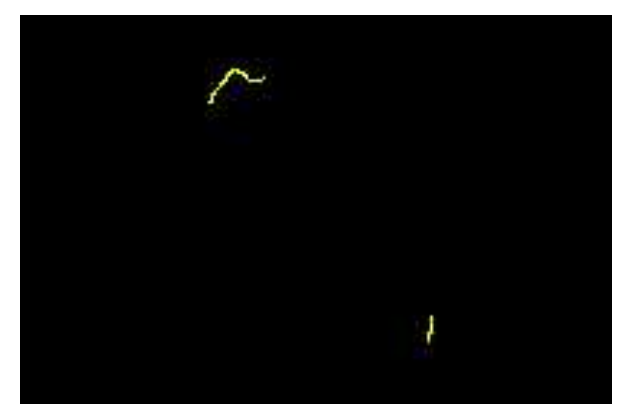

Gambar 12. Subtraction

Dan kurangkan citra Gambar 11 dari citra Gambar 10 yang akan menghasilkan Gambar 12.

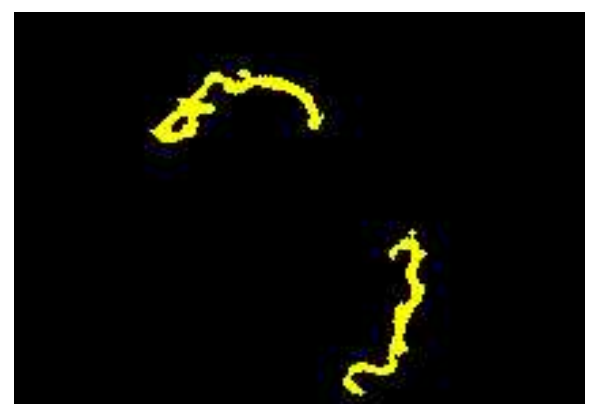

Gambar 13. Opening by reconstruction

Untuk menyelesaikannya, kita hanya harus merekonstruksikan gambar cacing filaria dari tail. Ini dilakukan dengan opening by reconstruction yang hasilnya adalah Gambar 13.

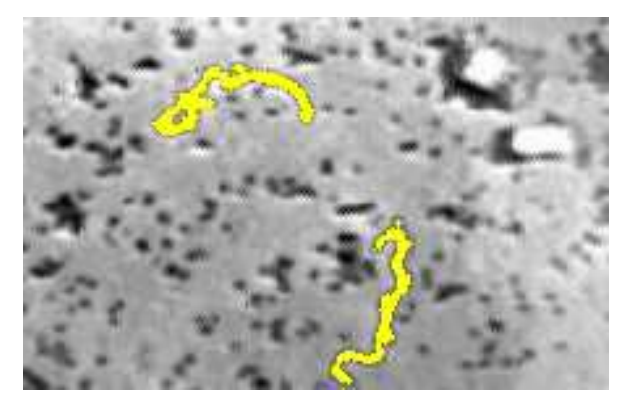

Gambar 14. Citra kombinasi

Gambar 14. adalah gambar kombinasi antara citra cacing filaria yang terekstraksi dan citra asli.

\section{KESIMPULAN}

Dari berbagai pembahasan yang telah dilakukan di atas, dapat disimpulkan sebagai berikut:

1. Struktur image thinning seringkali berhubungan dengan proses pengolahan citra yang lain, seperti subtraction, reconstruction, skele-toning, dan sebagainya.

2. Untuk melakukan thinning dapat memilih beberapa algoritma dari banyak algoritma yang tersedia, diantaranya adalah metode Stentiford dan metode ZhanSuen.

3. Algoritma Zhang-Suen memiliki efisiensi yang cukup baik dan implementasi yang cukup mudah namun kualitasnya termasuk relatif kurang baik dibandingkan dengan algoritma Stentiford.

4. Algoritma Stentiford memiliki efisiensi yang kurang dan implementasinya cukup sulit jika dibandingkan dengan algoritma Zhang-Suen.

\section{DAFTAR PUSTAKA}

Extraction of Filarial Worms [on-line].

Didapat dari

http://www.dca.fee.unicamp.br/pro jects/khoros/mmach/tutor/applicati on/biological/fila/fila.html; Internet; diakses tanggal 30 April 2007.

Mathematical Morpohology [on-line].

Didapat dari

www.imm.dtu.dk/ jmc/02501/lect ures/02501_morphology.pdf;

Internet; diakses tanggal 30 April 2007.

Selected Morphological Algorithm [online]. Didapat dari

http://documents.wolfram.com/app lications/digitalimage/UsersGuide/ 
6.5.html Internet; diakses tanggal 30 April 2007.

Thining [on-line]. Didapat dari http://vision.cse.psu.edu/resources/ hipr/html/thin.htm; Internet; diakses tanggal 30 April 2007.

Cheng, Ya-Lin dan Cherng-Min Ma.A Topology Preserving 4subiteration Gray-Level Thinning Algorithm [on-line]. Tersedia di: http://www.csie.mcu.edu.tw/ 〜yklee/CVGIP03/CD/Paper/IP/IP06.pdf; Internet; Diakses 30 April 2007.

Gonzalez, Rafael C and Richard E.Woods. 1992.Digital Image Processing. Addison- Wesley Publishing Company.

A. Jain,1989 Fundamentals of Digital Image Processing, Prentice-Hall. 